$\xi=-1$ 囬

\title{
Mobiles reinventing shopping: A critical review
}

\author{
Rhytheema Dulloo * \\ Assistant Professor (S.S)School of Management, Hindustan Institute of Technology and Science, HITS Chennai, India \\ *Corresponding author E-mail: dulloo.rhytheema@gmail.com
}

\begin{abstract}
The purpose of this paper is to provide clear understanding of the increasing use of mobiles for shopping to e-tailers by classifying and organizing an exhaustive review of prior theoretical literature. To conduct the review author draws a sample of 250 articles published from addressing mobile shopping behavior of customers. This paper provides foremost organized review of mobile shopping literature thus providing opportunities for brands to build a focused marketing tactic to enhance mobile shopper engagement, leading to increased sales.
\end{abstract}

Keywords: E-Tailors; Mobile Internet Technology; Mobile Apps; Mobile Shopping; Telecommunication.

\section{Introduction}

With the advent of Mobile Internet technology, nature of mobile shopping, its evolution has been taking shape and turn significantly. Mobile internet technology provides unique benefits (high connectivity, ubiquitous computing, personalization, convenience) making it a preferred choice among customers (Pantano, E et al., 2016). More than one third of all electronic transactions takes place in B2C industries through mobile devices nowadays, it is found that in majority of the countries consumers prefer making etail purchases via smartphones as opposed to portable personal computers (Criteo, 2016). The effect of mobile technology has been noticed by the e-tailers and as a result e-tailers have started reaching out to their customers through mobile shopping. Inman and Nikolova (2017) draw attention to how technologies can benefit both consumers and businesses, which ultimately enhance the businesses' profitability.

Mobile Shopping is a part of $\mathrm{m}$-commerce. "Mobile shopping is a mobile service that allows customers to browse or purchase products and services through mobile devices anytime, anywhere over the wireless telecommunication network" (Hung et al., 2012; Lu and Su, 2009; Yang and Kim, 2012). Mobile Shopping comprises of any such transactions that involves "transfer of ownership or rights to use goods and services, which is initiated by using mobile access to internet-mediated networks with the help of mobile devices."

While mobile shopping is gaining popularity not much research has been done in this area. Consumer behavior towards shopping has been an area of research for decades among academicians. In the fast changing retail landscape, consumers' needs still control their purchase decisions, (Grewal, D et al., 2017). This study attempts to provide a comprehensive literature review of prior studies on consumers mobile shopping behaviour. The aim of this paper is to provide an insight into consumers mobile shopping behavior thus providing opportunities for brands to build a focused marketing tactic to enhance mobile shopper engagement, leading to increased sales.

\section{Research methodology}

An orderly approach is used to ensure the eminence for proposed literature framework on mobile shopping (Levy and Ellis, 2006). The following research approach is selected (Doherty and EllisChadwick, 2006):

- Online indexes used: 10 online databases were used for the search, (1) ABI/INFORMS Database (Proquest), (2) Emerald (3) EBSCOhost (4) IEEE Xplore Digital library (5) Inderscience Publishers (6) JSTOR (7) SAGE journals (8) ScienceDirect (9) SpringerLink Online Library (10) Wiley Online Library. Google Scholar is also used for extensive search results.

Phrases used for literature search: "mobile shopping", "m shopping", and "m-shopping" were considered and were relevant among chosen databases.

- $\quad$ Timeframe considered: for the literature review year 2000 is chosen as the starting point. "Prior to 2000, significant publications on $\mathrm{m}$-commerce or m-shopping topic in particular are not available (Lamarre et al, 2012; Varnali and Toker, 2010)." Consequently, only articles published between 2000 and 2017 are considered.

Literature articles identified for research: restricted to peer-reviewed journal papers published. Term based search is matched by a separate content review to eliminate all such articles that are not within proposed framework of this research. 


\section{Classification of mobile shopping literature}

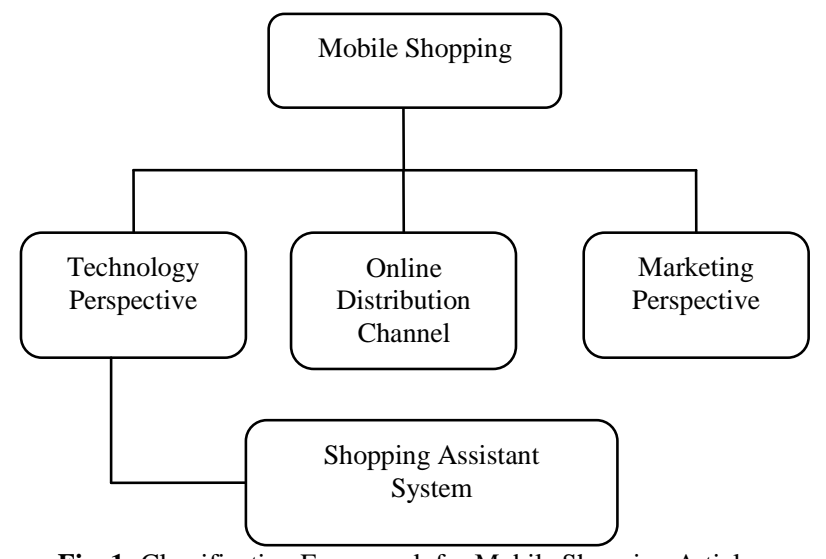

Fig. 1: Classification Framework for Mobile Shopping Articles.

\section{Literature review}

"Consumer behaviour has changed over the past few decades, but it has been evolutionary and the seeds of changes have been apparent for generations," (Kar, 2010). The collected literature has been reviewed as:

\subsection{Meaning and concept of mobile shopping}

Shopping via mobile started from the end of twentieth century. New millennium witnessed a swift market evolution of mobile applications. Real time shopping through mobiles appears to create way for mobile business.

Mobile Shopping may be defined as "purchase of goods or services from mobile devices such as smartphones and tablets via wireless network," (Wu \& Hisa, 2004) and has become very popular among online shoppers. With context to present approaches in the emerging field of mobile shopping (Barnes, 2002), "smartphone-based mobile shopping is defined as commercial transactions conducted through smartphones over a wireless telecommunication network." In general, m-shopping can be portrayed as a superior m-service that permits customers to surf or purchase products and services from e-tailers via mobile devices anywhere, anytime (Hung et al., 2012; Lu and Su, 2009; Yang and Kim, 2012). Wong et al. (2012, p. 25) regard m-shopping as "any monetary transactions related to purchases of goods or services through internet-enabled mobile phones or over the wireless telecommunication network", and Lai et al. (2012, p. 387) state that mobile shopping lets buyers gather real-time information from several sources, check on products available, deals and discounts offered, price comparisons and alter their assortment at any time during purchase process. Thus $\mathrm{m}$-shopping is considered to be a new and vital element of mobile marketing (Barutçu, 2007, 2008; Lamarre et al., 2012). Yang (2010), highlights the potential of mshopping services as a personal assistant for shoppers, optimizing their purchase experience in a brick-and-mortar shop environment by designing a real-time, personalized interactive sales channel between e-tailers and consumers; promising disruptive mobile marketing that cater to the interests, likes and concerns of customers; helping smart customers of today in making smart purchase decisions. The most striking feature of mobile shopping is its accessibility anytime and anywhere (McCloskey, 2006; Balasubramanian, Peterson, \& Jarvenpaa, 2002). Ease of use, convenience, variety of products to choose from, price comparisons, discounts, deals etc has made it popular among the masses. Retailers are looking to capitalize on this new form of technology to increase their sales. Abu Bakar and Osman (2005) defines mobile commerce as "exchange of buying and selling of commodities and services through wireless handheld devices such as cellular telephones and personal digital assistant". Mobile Commerce is considered to be new service frontier, (Kleijnen et al. 2007).

\subsection{Factors and determinants influencing the customers in mobile shopping}

Manzano et al. (2009), assessed role played by personality variables like innovativeness, affinity, compatibility in transforming impact of TAM constructs on behavioral acceptance intention of purchasing via mobiles. Personality variables like innovativeness, affinity to mobiles, and compatibility were found to strongly influence intention to purchase via mobiles thus revealing that effect of perceived usefulness and perceived ease of use are extended in absence of personality variables. Ko et al. (2009), revealed "mcommerce characteristics consisting of four factors: usefulness, enjoyment, ease of use, and instant connectivity. The first three factors were positively related to perceived value, whereas instant connectivity was negatively related. Moreover, estimated structural equation modeling described the important function of perceived value as mediating the effect of $\mathrm{m}$-commerce characteristics on the consumers' intention to adopt mobile fashion shopping." Shankar et al. (2010), in his study highlighted that disruptive mobile marketing and widespread of mobile internet technology has created a paradigm shift from traditional shopping to a new virtual retail environment based on e-tailers anytime, anywhere access to the consumers through their mobile devices. Persaud et al. (2012), explored consumers acceptance of shopping through smartphones. They revealed consumers style of shopping, faith towards brand and value are prime reasons which influence consumers to shop through smartphones. Chong (2012), in a study on "Predicting m-commerce adoption determinants: A neural network approach" expanded Unified theory of acceptance and use of technology (UTAUT) model to study determinants of $\mathrm{m}$ commerce acceptance. Further variables such as perceived value, perceived enjoyment, trust and personal innovativeness were incorporated in the model. Adoption of mobile commerce was studied using neural network approach. The expanded UTAUT model showed "perceived value and trust have more important role than original UTAUT model." Results also showed younger consumers are more likely to use mobile commerce. Therefore mobile app providers should focus on targeting older consumers and the values which mobile commerce apps can offer. "Consumer technology traits in determining mobile shopping adoption: An application of the extended theory of planned behavior" in a study done by Yang et al., 2013, it was found positive attitude towards mobile shopping among customers is a result of perceived enjoyment. Further it was proved that there is a difference in levels of consumer technology traits like technology innovativeness, experience of using technology etc. when it comes to consumer behaviour towards shopping via mobiles. Hendrix Phi (2013), studied mobile shopping apps consumers value most and found apps that provide easy navigation, price comparisons, allow managing rewards and loyalty are valued most by the consumers. Holmes et al. (2013), studied mobile shopping behavior using variables like attitude, shopping process involvement and location. Their study revealed convenience and accessibility are valued most by the mobile shoppers. Malik, A et al. (2013), studied predictors of Mcommerce and their results revealed that "perceived usefulness and perceived ease of use significantly affect acceptance of mcommerce while perceived financial risk adversely impacts the acceptance of $\mathrm{m}$-commerce by consumers. Alongside these factors, other variables like personal innovativeness and product involvement were also found to be strong predictors."

According to Kang et al. (2015), mobile apps usage is driven by convenience which in turn is the reason for recent increase in mobile shopping.. Mitok (2015), in her study on "How mobile apps are changing consumer behaviour: A case of Alberta Culture Events Mobile App" highlighted the way brands are interacting with consumers is changing. Now mobile apps are becoming a powerful technological and marketing tool used by e-tailers to target the consumers, so it becomes imperative to focus attention on data and information being delivered through this medium as it has the power to transform an app into a personal digital assistant. The study found features like personalization, design, security and 
brand positively influence consumers behaviour towards using an app. Musa et al. (2015), studied "predictors and consequences of consumers attitude towards mobile shopping applications." The study revealed that features of mobile applications is the most influensive predictor of consumers attitude while confidentiality and security the least significant predictor. Tung et al. (2015), explored relationship between mobile shopping characteristics, website interaction, consumer shopping behavior and website app loyalty by conducting research on 269 consumers who experienced mobile shopping. It was found that increase in rate of shopping via mobile will not have an impact on Website App Loyalty. Pantano et al. (2016), studied scale of influence of mobile technologies on consumer behavior in their study on "effect of mobile retailing on consumers purchasing experiences: a dynamic perspective" with focus on drivers stimulating consumers to push towards m-shopping. Their findings also showed consumers are shifting from electronic to mobile channels. Groß (2016), in his study found, "due to monetary transactions involved in mobile retailing the main drivers of consumers acceptance relate to risk avoidance, which includes the trust in the transaction, privacy concerns and network security." Jelena (2016), explored factors affecting intention of consumers behaviour to use mobile apps for purchasing fashion goods in Sweden. It was found that consumers hedonic motivation, performance expectancy, facilitating conditions and habit has significant impact on intention to use m- apps for purchasing fashion goods. Chian et al. (2017), explored "Impact of utilitarian and hedonic value on satisfaction and continuance intention of mobile phone applications." The study highlighted that perceived utilitarian value has a great influence on perceived playfulness. Results also supported that satisfaction in technology results in users continuance intention. Newman et al. (2017), in a study on "Bricks or Clicks? Understanding consumer usage of retail mobile apps" revealed consumers personally connect to mobile apps due to 'ease of use' attribute of mobile apps. It was also found to have a great impact on their preference for mode of purchasing channel, actual purchasing behaviour and suggesting it to others. Gupta, A et al. (2017), examined the mobile shopping adoption using a novel approach of behavioral reasoning theory, to test the relative influence of reasons for, and importance of reasons against adoption of mobile shopping among Indian consumers, the findings support that 'reasons for' and 'reasons against' are prime determinant of attitude and intentions. Among the reasons for, price saving orientation is the major determinan for mobile shopping adoption and among the reasons against, self efficacy is the major determinant against adopting mobiles for shopping. The results also prove that that value of "openness to change" has a strong impact on reasons for adoption but not on reasons against adopting mobiles for shopping. Tak et al. (2017), predicted mobile app based shopping using Unified Theory of Acceptance and Use of Technology model(UTAUT) and revealed that hedonic and habit are major determinants of users behavioral intention to use mobile app. It was also found deals offered by marketers plays a critical role in influencing customers. Zurich et al. (2017), studied mobile app adoption by consumers in different life stages and found that consumers present lifestage has a great impact on his mobile app adoption patterns.

\subsection{Mobile shopping buying behaviour pattern}

Bigné, E., et al. (2009), highlighted that M-shopping buying behavior pattern can be predicted from consumers age and experience as Internet user and shopper. The level of customers purchase ability using mobile motivates or demotivates their acceptance of mobile shopping as per a study done by Jayawardhena et al., (2009). Acceptance of mobiles for shopping was found to be significant in a study done by Holmes et al. (2013), but it is less when compared with shopping via desktops. The study highlighted that majority of the customers value convenience and excessively use mobiles primarily during information search phase than during actual purchase transaction phase. In the phase of decision making higher level of involvement with mobile devices was found for higher involvement goods in relation to all the phases of decision making process. Most of the mobile shoppers preferred to shop from their home which supports previous studies results stating that customers value convenience and easy accessibility when it comes to shopping. In an empirical study done by Groß, 2015 results show that overall risk perception towards mobile channels hinders consumers from regularly engaging in $\mathrm{m}$ shopping. It was stated, "it is more transaction-processing and financial risks rather than privacy or security concerns that are significant aspects for experienced mobile shoppers." While making a decision whether to purchase via a mobile medium or not, constructs like convenience and emotional values were used in a study done by Assarut, R and Eiamkanchanalai, S (2015) and it was found the above two constructs form the universal values which consumers consider while purchasing fashion goods via mobiles. Agrebi and Jallais (2015) extended TAM model by adding satisfaction towards the visit of the mobile Web site and the perceived enjoyment to study smartphone users intention of mobile shopping. The outcome underlined two difference between the customers profiles, "the first was the positive and significant impact of perceived enjoyment on the intention to use smartphones to make purchases and the second difference concerns the impact of satisfaction on the intention to use smartphones for purchases, which is significant only among the purchasers."

In a study done by Wang et al., 2015 "On the Go: How Mobile Shopping Affects Customer Purchase Behavior", "as customers adopt M-shopping, number of orders placed per year, i.e., Order rate, increases. Especially for low-spending customers, both their order rate and order size, increase as they become accustomed to M-shopping. In addition to the effect on customer's spending behavior, it was also found that M-shoppers tend to use mobile devices to shop for habitual products that they already have a history of purchasing. It was proposed that customers utilize mobile devices because the technology provides convenient access, which leads them to incorporate M-shopping into their habitual routines." It was also found that the main consumers' intentional behavior is to share the information in a study on "The Predictors and Consequences of Consumers' Attitude Towards Mobile Shopping Application" done by Musa, R et al., (2016). Kuoppamäki et al., (2017) in their study revealed that consumers aged 55 to 74 use a smartphone or tablet to purchase products or services online as often as younger consumers. Their results demonstrated that mobile-based online shopping is best predicted by age, higher education, and household type (children living at home), and use of entertainment media by age and gender.

In a study on mobile fashion apps done by Hur et al. (2017), based on the Technology Acceptance Model (TAM), app users were placed into two categories: one category was of those with high technological innovativeness and second category was of those with high fashion innovativeness. Those on higher side of technological innovativeness used apps due to its ease of use and satisfaction they derived out of it and continued using it if they found it to serve their needs. While those on higher side of fashion innovaiveness merely used fashion app for fun and not for reason of any benefit. Further, study also compared millennials with their mature counterparts and explored how generational differences impacted innovative mobile marketing technology thus improving the understanding of buying behaviour of different generations towards mobile shopping. Natarajan et al., (2017), found price sensitivity among mobile shoppers depends on their level of innovativeness towards technology and intention to use mobile apps for shopping. Higher the extent of technological innovativeness and intention to use mobile apps, lower will be the price sensitivity. Mobile app adoption pattern was found to be strongly influenced by shoppers current life stage as per a study by Frey et al., 2017. 


\section{Conclusion}

Beck and Lynch (2001), "The ability to shop online without leaving the home and to have the products delivered to the door is of great interest to many shoppers." $60.83 \%$ of Indians prefer shopping via mobiles (Dazinfo, 2016). This paper contributes to emergent research field of mobile shopping by reviewing past literature. In relation to previous research, the commonly cited determinants for shopping via mobile have been perceived ease of use, personal innovativeness, convenience, price saving, perceived usefulness and trust. Trust is more significant than other antecedents (Wang and Barnes, 2007). The suggestion for e-retailers is that promises, commitments made to mobile shoppers should be fulfilled in order to build strong bond of trust between the customers and the vendors. This also includes delivering correct and good quality products, providing right description of products on mobile apps. This will have a positive influence on consumers acceptance of mobile shopping. Innovative promotional and pricing tactics should be employed to draw upon price-conscious customers. Social networks, informal seminars can be used to attract customers towards mobile shopping (Lu et al., 2008). It was also found deals offered by mobile vendors play a vital role in influencing customers. Retailers can present mobile exclusive offers and also exclusive range for mobile shoppers. The study also shows that introduction of mobiles has transformed the practice of shopping in numerous ways. Consumers can use mobiles to check prices, read reviews of products online, make shopping list, consult blogs, photograph products, get information on products, ask for online help and much more. While not changing the practice of shopping i.e., acquiring of products, letting them access, store, and process information in new ways, providing new ways of communication thus providing them with new experience of shopping. Using mobiles to shop cannot be seen as a new practice, but, it re-configures the practice of shopping.

Retailers will be myopic in their view if they only look at bright side of mobile shopping. This study confirms that reasons against mobile shopping adversely impacts acceptance of mobile shopping. It was found risk related to financial transactions, network security, privacy concerns, are the roadblocks hindering mobiles from becoming widely accepted by today's consumers. Thus, retailers should design secured mobile retail apps and also provide immediate exchange or refund services to shoppers. Technical improvements are also strongly recommended to lessen transactional processing errors caused by unsteady internet connection and dead spots. It is also necessary for retailers to find ways to reduce stress and anxiety among mobile shoppers by delivering functions that allow tracking of their expenditures and placing a limit on what they spend online.

Based on these insights, retailers can establish apt mobile capabilities to support the needs of mobile-enabled shopper. This study is imperative for e-tailers as it will help them to build a focused marketing tactic to enhance mobile shopper engagement, leading to positive impact to the increase in growth of sales.

\section{References}

[1] S. Balasubramanian, R. A. Peterson and S.L. Jarvenpaa, "Exploring the implication of m-commerce for markets and marketing", Journal of the Academy of Marketing Science, vol.30 No 4, pp. 348-361, 2002

[2] S.J. Barnes, "The mobile commerce value chain: Analysis and future development", International Journal of Information management, vol.22 No2, pp.91-108, 2002.

[3] J.-H.Wu and T.-L. Hisa, "Analysis of e-commerce innovaiton and impact: A hypercube model,", Electronic Commerce Research and Applications, vol.3 No.4, pp. 389-404, 2004

[4] Wu, J. H., \& Wang, S. C. "What drives mobile commerce? An empirical evaluation of the revised technology acceptance model". Information \& management,vol. 42 No.5, pp.719-729, 2005.

[5] E. Bigné,C. Ruiz,S. Sanz, "The impact of internet user shoppingpatterns and demographics on consumer mobile buying behaviour", Journal of Electronic Commerce Research, Vol.6 No.3, 2005.

[6] D.W. McCloseky, "The importance of ease of use, usefulness and trust to online consumers: An examination of the Technology Acceptance Model with older consumers", Journal of Organizational and End User Computing, vol. 18 No.3, pp48-65, 2006.

[7] N.F. Dohetry and F.E. Chadwick, "New perspectives in internet retailing: a review and strategic critique of the field", International journal of Retail \& Distribution Management, vol.34 Nos4/5,pp.411-428, 2006.

[8] Y. Levy and T.J. Ellis, "A systems approach to conduct an effective literature review in support of information systems research", Informing Science Journal, vol. 9 pp. 181-212, 2006.

[9] S. Barutçu, "Attitude towards mobile marketing : a study of turkish customers", Journal of Targeting, measurement and Analysis for Marketing, vol.16 No.1, pp.26-38, 2007.

[10] C. Jayawardhena, A. Kuckertz, H.Karjaluoto and T. Kautonen, "Antecedents to permission based mobile marketing: an initial examination", European journal of Marketing, vol. 43 No.3/4, pp.473-499, 2009.

[11] J. A. Manzano, C.R. Mafe, S.S. Blas"Exploring individual personality factors as drivers of M-shopping acceptance", Industrial management and data systems, vol.109 No.6, pp. 739-757, 2009.

[12] E. Ko, E.Y. Kim and E.K. lee, "Modeling consumer adoption of mobile shopping for fashion products in Korea", Psychology \& marketing, vol. 26 No. 7, pp.669-687, 2009.

[13] H.-P. Lu, P.Y.J. Su, "Factors affecting purchase intention on mobile shopping websites", Internet Research, vol. 19 No. 4, pp. 442-458, 2009.

[14] M. Kleijnen, K.de. Ruyter, M. Wetzels, "An assessment of value creation in mobile service delivery and the moderating role of time consciousness", Journal of Retail, vol. 83 No.1, pp.33-46, 2009

[15] K. Varnali, A. Toker, "Review : mobile marketing research: the state-of-the-art", International Journal of Information management, vol.30, pp.144-151, 2010.

[16] M. Kar, "Consumer Behaviour over the last 25 years", Oxirm Research themes, Oxford Institute of Retail management, The Retail Digest, pp46-53, 2010.

[17] V. Shankar, A. Venkatesh, C. Hofacker, and P. Naik, "Mobile amrketing in the retail environment: current insights and future research avenues", Journal of Interactive Marketing, vol. 24 No.2, pp.111-120, 2010.

[18] K. Yang, "Determinants of US consumer mobile shopping services adotpion:implications for designing mobile shopping services", Journal of consumer marketing, vol.27 No.3, pp. 262-270, 2010

[19] A. Chong, " Predicting m-commerce adoption determinants : A neural network approach", Expert systems with Applications: An International Journal, vol. 40 No.2, pp. 523-530, 2012

[20] A. Persaud and I. Azhar, "Innovative mobile amrketing via smartphones: are customers ready?", Marketing Intelligence and Planning, vol.30 No.4, pp. 418-443, 2012.

[21] A. Lamarre, S. Galarneau and H. Boeck, "Mobile marketing and consumer behaviour current research trend", International Journal of Latest Trends in Computing, vol.3 No.1, pp.1-9, 2012.

[22] C.H. Wong, H.S. Lee, Y.H. Lim, B.H. Chua and G.W.H. Tan, "Predicting the consumers' intention to adopt mobile shopping: An emerging market perspective," International Journal of Network and Mobile Technologies, vol.3 No.3, pp.24-39, 2012

[23] C. Aubrey and D. Judge, "Re-imgine retail: why store innovation is a key to brand's growth in the 'new normal', digitally connected and transparent world", Journal of Brand Strategy, Vol. 1 No.1, pp. 3139, 2012.

[24] K. Yang, "Consumer technology traits in determining mobile shopping adoption: an application of the extended theory of planned behavior", Journal of retail and consumer services, vol 19 No 5, pp.489-491, 2012.

[25] M.C. Hung, S.T. Yang, T.C. Hsieh, "An examination of the determinants of mobile shopping continuance", International journal of electronic business management, vol. 10 No. 1, pp.29-37, 2012.

[26] K. Yang and H. Kim, "Mobile shopping motivation: an application of multiple discriminant analysis", International Journal of retail and Distribution, vol. 40 No.10, pp.779-789, 2012.

[27] A. Holmes, A. Byrne, J. Rowley, "Mobile shopping behaviour: insight into attitudes, shopping process involvement and location", International Journal of retail and distribution management, vol 42 No. 1, pp. 25-39, 2013. 
[28] A. Malik, R. Kumra and V. Srivastava, "Detreminants of Consumer Acceptance of M-Commerce", South Asian Journal of Management, 2013.

[29] K. Yang, J.C. Forney, "The moderating role of consumer technology anxiety in mobile shopping adoption: differential effects of facilitating conditions and social influences", Journal of Electronic Commerce research vol.14 No 4, pp. 334-347., 2013.

[30] R. Assarut and S. Eiamkanchanalai,"Consumption values, Personal Charcteristics and Behavioral Intentions in Mobile Shopping Adoption", Trziste, UDK 658.842:621.395.721.5 366.12.

[31] K. Peng, Y. Chen and K. Wen, "Brand relationship, consumption values and branded app adoption", Industrial management \& Data Systems, Vol. 114 No. 8, pp. 1131-1143, 2014.

[32] M. Groß, "Exploring the acceptance of technology for mobile shopping: an empirical investigation among smartphone users". The International Review of Retail, Distribution and Consumer Research, vol.25 No.3, pp.215-235, 2015.

[33] R.J. Wang, E.C. Malthouse and L. Krishnamurthi, "On the go: how mobile shopping affects customer purchase behavior", Journal of Retailing, vol. 91 No.2, pp.217-234, 2015.

[34] S. Agrebi, and J. Jallais, "Explain the intention to use smartphones for mobile shopping", Journal of Retailing and Customer Services, vol.22. pp.16-23, 2015

[35] J.Y. Kang, M.J. Mun and K.K.P. Johnson, "In-store mobile usage: downloading and usage intention toward mobile location-based retail apps", Computers in Human Behavior, vol. 46, pp.201-217, 2015.

[36] Critoe., State of mobile commerce 2016. http://www.criteo.com/de/resources/criteo-ecommerce-industryoutlook-2016/.

[37] E. Pantano, C.V. Priporas, "The effect of mobile retailing on consumers purchasing experience: a dynamic perspective, Computers in human behavior, vol.61 No.8, pp. 548-555, 2016.

[38] M. Groß, "Impediments to mobile shopping continued usage intention: A trust-risk-relationship". Journal of Retailing and Consumer Services, vol 33(November ), pp.109-111, 2016

[39] R. Musa, S. Janiffa, M.H.M. Harun, A.A. Adam, D.F.Dzahar, S.S haussain, W.M.W.Lokman, "The predictors and consequences of consumers' attitude towards mobile shopping application", Procedia economics and Finance, vol.37, pp.447-452, 2016.

[40] C.-L.Hsu, K.-H.Kuo,A.-Y.Hsieh, C.-C.Tang, "The impacts of utilitarian and hedonic value on satisfaction and continuance intention of mobile phone applications: The mediating roles of flow experience and perceived playfulness", Journal of Quality, vol.24 No.3, pp.191-201, 2017.

[41] D. Grewal, A. Roggeveen, and J. Nordfalt," "The future of Retailing,"vol. 93, pp. 1-6, 2017.

[42] C.L. Newman, K. Wachter, A. White, "Bricks or Clicks? Understanding consumer usage of retail mobile apps", Journal of Services marketing, vol.32 No.2, pp.211-222, 2017

[43] J. J. Inman, H. Nikolova,"Shopper-facing retail technology:An adoption decision calculus", Journal of Retailing, vol.93 No.1, 2017.

[44] R.M. Frey, R. Xu, A.Ilic, "Mobile app adoption in differne tlife stages: An empirical analysis", Pervasive and Mobile computing, vol.40, pp.512-527, 2017.

[45] S.-M. Kuoppamäki, S. Taipale, and T.-A. Wilska, "The use of mobile technology for online shopping and entertainment among older adults in Finland", telematics and Informatics, vol.34 No.4, pp.110-117, 2017.

[46] R.M. Frey, R. Xu, A.Ilic," Mobile app adoption in different life stages:An empirical analysis", Pervasive and Mobile Computing, vol. 40 No.C, pp 512-527, 2017.

[47] T. Natarajan, S.A. Balasubramanian, D.L. Kasilingam, "Understanding the intention to use mobile shopping applications and its influence on price sensitivity", Journal of Retailing and Consumer Services, vol. 37, pp. 8-22, 2017.

[48] A. Gupta, N. Arora, "Understanding determinants and barriers of mobile shopping adoption using behavioral reasoning theory", Journal and Retailing of Consuemr Services, vol.36, pp.1-7, 2017.

[49] P.Tak, S. Panwar, "Using UTAUT 2 model to predict mobile app absed shopping:evidences from India", Journal of Indian Business Research, vol. 9 No.3, pp.248-264, 2017.

[50] H.J. Hur, H.K. Lee, H.j.Choo,"Understanding usage intentionin innovative mobile app service", Computers in human behavior, vol.73, No.C, pp. 353-361, 2017. 